\title{
Vitamins D, C, and $E$ in the prevention of type 2 diabetes mellitus: modulation of inflammation and oxidative stress
}

\author{
Bibiana Garcia-Bailo',2 \\ Ahmed El-Sohemy ${ }^{2}$ \\ Pierre S Haddad ${ }^{3}$ \\ Paul Arora ${ }^{1,4}$ \\ Firas BenZaied ${ }^{5}$ \\ Mohamed Karmali ${ }^{1,2,4}$ \\ Alaa Badawi' \\ 'Office for Biotechnology, Genomics \\ and Population Health, Public Health \\ Agency of Canada, Toronto, ON, \\ Canada; ${ }^{2}$ Department of Nutritional \\ Sciences, University of Toronto, \\ Toronto, ON, Canada; ${ }^{3} \mathrm{Natural}$ \\ Health Products and Metabolic \\ Diseases Laboratory, Department \\ of Pharmacology, Université de \\ Montréal and Montreal Diabetes \\ Research Centre, Montreal, QC, \\ Canada; ${ }^{4}$ Dalla Lana School of Public \\ Health, University of Toronto, Toronto, \\ ON, Canada; ${ }^{5}$ Canadian College of \\ Naturopathic Medicine, Toronto, \\ ON, Canada
}

This article was published in the following Dove Press journal:

Biologics: Targets \& Therapy

I 8 January 201 I

Number of times this article has been viewed

\begin{abstract}
The incidence of type 2 diabetes mellitus (T2DM) is increasing worldwide, and certain population subgroups are especially vulnerable to the disease. To reduce T2DM risk and progression at the population level, preventative strategies are needed that can be implemented on a population-wide scale with minimal cost and effort. Chronic low-grade inflammation resulting from oxidative stress and imbalances in the innate immune system has been associated with obesity, metabolic syndrome, and insulin resistance - critical stages in the development and progression of T2DM. Therefore, inflammation may play a causal role in the pathogenesis of T2DM, and reducing it via modulation of oxidative stress and the innate immune response could lead to a status of improved insulin sensitivity and delayed disease onset. Dietary supplementation with anti-inflammatory and antioxidant nutritional factors, such as micronutrients, might present a novel strategy toward the prevention and control of T2DM at the population level. This review examines current knowledge linking oxidation, inflammatory signaling pathways, and vitamin supplementation or intake to the risk of T2DM. The concept that micronutrients, via attenuation of inflammation, could be employed as a novel preventive measure for T2DM is evaluated in the context of its relevance to public health.
\end{abstract}

Keywords: type 2 diabetes, oxidative stress, innate immunity, inflammation, micronutrients

\section{Introduction}

Type 2 diabetes mellitus (T2DM) has reached global epidemic proportions. The disease affects over 150 million people worldwide, a number that is expected to double by $2025 .^{1}$ It is estimated that six people die every minute from T2DM globally, a figure that will soon make the disease one of the world's most prevalent causes of preventable mortality. ${ }^{2}$ Rates of disease incidence increase with age, obesity, and a sedentary lifestyle, are elevated in certain ethnicities (Hispanics, Africans, and Aboriginals), and have been increasingly noted in children. ${ }^{3,4}$

T2DM is a multifactorial disease characterized by chronic hyperglycemia, altered insulin secretion, and insulin resistance - a state of diminished responsiveness to normal concentrations of circulating insulin. ${ }^{5,6} \mathrm{~T} 2 \mathrm{DM}$ is also defined by impaired glucose tolerance (IGT) that results from islet $\beta$-cell dysfunction, followed by insulin deficiency in skeletal muscle, liver, and adipose tissues. ${ }^{78}$ In individuals with IGT, the development of T2DM is governed by genetic predisposition and environmental variables (a hypercaloric diet and the consequent visceral obesity or increased adiposity in liver and muscle tissues) and host-related factors (age, imbalances in oxidative stress, and inflammatory responses) $)^{1,5,9-16}$ (Figure 1). Clinical complications of T2DM include both microvascular diseases (eg, retinopathy, nephropathy, and neuropathy) 


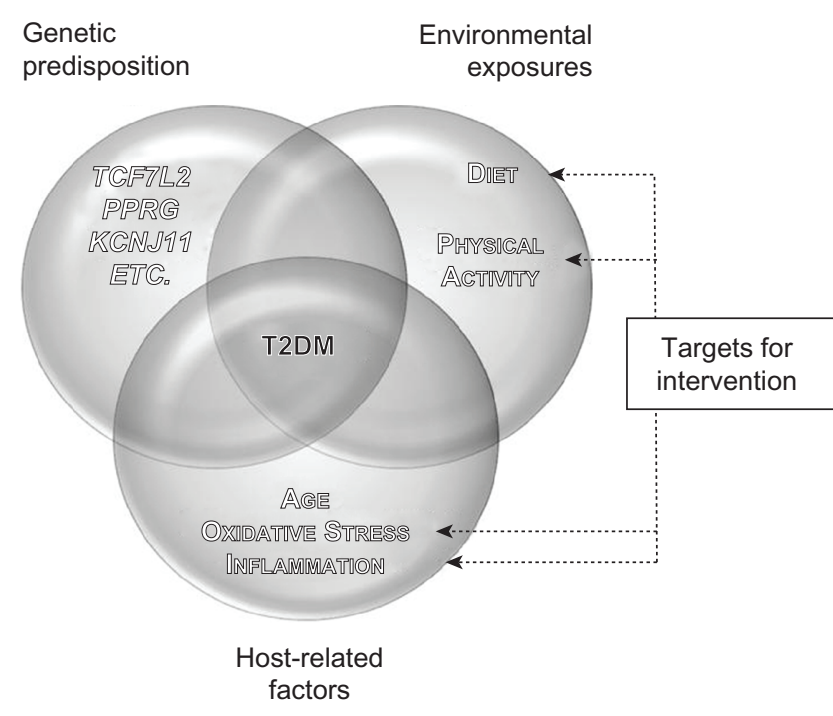

Figure I Interaction between genetic predisposition, environment, and host-related factors affecting T2DM and potential areas of focus for intervention. The development of T2DM results from the interaction between genetic predisposition, environmental exposures, and various host-related factors. single-nucleotide polymorphisms within several genes, such as TCF7L2, PPARG, and KCNJII, have been associated with T2DM risk via candidate gene studies and genome-wide associations. Lack of physical activity and a hypercaloric diet, with the resulting visceral obesity and increased adiposity in liver and muscle tissue, are associated with T2DM risk as well. Finally, host-related factors such as age, oxidative stress, and chronic inflammation also play a role in the development of the disease. Therapeutic interventions aimed at modifying lifestyle and/or levels of oxidative stress and chronic inflammation may aid in T2DM prevention and control.

and macrovascular complications (eg, myocardial infarction, peripheral vascular disease, and stroke). ${ }^{5}$ The macrovascular diseases are considered to be the leading cause of mortality among diabetics. ${ }^{17}$

A significant body of evidence highlights the key role of abnormal innate immune responses and chronic low-grade inflammation in the pathogenesis of insulin resistance and the development of T2DM..$^{9,18-20}$ Inflammation results from the activation of the innate immune response - the body's immediate, nonspecific reaction against environmental insults such as pathogens and chemical or physical injury. ${ }^{9}$ Inflammation plays a role in prevention of tissue damage, restoration of tissue homeostasis, and destruction of infectious agents. ${ }^{9,21}$ It is the result of the acute phase response, a systemwide process during which several proinflammatory cytokines, such as tumor necrosis factor (TNF)- $\alpha$, interleukin (IL)-1 $\beta$, and IL-6, are released, primarily by macrophages. ${ }^{22}$ These cytokines can enhance insulin resistance directly in adipocytes, muscle, and hepatic cells, ${ }^{23,24}$ leading to systemic disruption of insulin sensitivity and impaired glucose homeostasis. ${ }^{25}$ Increased levels of proinflammatory cytokines lead to hepatic production and secretion of acute-phase proteins such as C-reactive protein (CRP), plasminogen activator inhibitor-1 (PAI-1), amyloid-A, $\alpha 1$-acid glycoprotein, and haptoglobin.
These proteins, collectively known as inflammatory markers, appear in the early stages of T2D, and their circulating concentrations increase as the disease progresses. ${ }^{20,26}$

Chronic inflammation is closely associated with oxidative stress, an exaggerated presence of highly reactive molecular species, which leads to potential tissue damage. ${ }^{10,27}$ Oxidative stress results either from an increase in free radical production, a decrease in endogenous antioxidant defenses, or both. ${ }^{5,28,29}$ Obesity and the metabolic syndrome, conditions which are considered key steps in the progression of insulin resistance to T2DM, are associated with both oxidative stress and inflammation. ${ }^{8,30,31}$ Hyperglycemia, increases in plasma levels of free fatty acids (FFAs), and hyperinsulinemia have all been linked to increased production of reactive oxygen species (ROS) and reactive nitrogen species (RNS). ${ }^{10,32-36}$ ROS and RNS activate nuclear factor $\kappa \mathrm{B}(\mathrm{NF} \kappa \mathrm{B})$, a proinflammatory transcription factor, that triggers a signalling cascade leading to a continued synthesis of oxidative species and the low-grade chronic inflammation. ${ }^{37-39}$

Given that obesity and the metabolic syndrome are steps toward the development of T2DM, their link with oxidative stress and inflammation points to a potential causative role for these factors in the progression of the disease. ${ }^{8}$ Thus, aiming to reduce oxidative imbalances and inflammation could lead to improved insulin sensitivity and delayed disease onset. Measures that prevent the development of oxidative stress and inflammation may present a feasible strategy for T2DM prevention and control. Dietary intake of micronutrients has been associated with reduced levels of oxidative stress, proinflammatory cytokines, and risk of T2DM in various cross-sectional and interventional studies, ${ }^{8,40-45}$ an approach that may facilitate the development of novel strategies for the prevention of T2DM.

This review was undertaken in an attempt to examine current knowledge linking micronutrients intake to oxidation and inflammatory signaling pathways in the pathogenesis of T2DM. The possibility that attenuating oxidative stress and inflammation by micronutrients can be employed as a novel approach for the prevention of T2DM is evaluated from the public health perspective.

\section{Oxidative stress, inflammation, and T2DM}

Oxidation is a chemical process whereby electrons are removed from molecules and highly reactive free radicals are generated. ${ }^{40}$ Free radicals include ROS such as superoxide and hydroperoxyl and RNS such as nitric oxide and nitrogen dioxide..$^{5,10,17}$ Reactive species arise as natural by-products 
of aerobic metabolism, and they play a role in numerous signaling cascades and physiological processes, such as phagocytosis, vasorelaxation, and neutrophil function. . $^{5,17,46,47}$ However, excessive oxidation can trigger cytotoxic chain reactions that are damaging to membrane lipids, proteins, nucleic acids, and carbohydrates. ${ }^{17,27,46,48}$ Therefore, the capacity of serum to control production of free radicals is defined as the 'total antioxidant status'.

The signaling transduction role of ROS stems from their ability to activate a number of stress-sensitive kinases whose downstream effects mediate insulin resistance. ${ }^{10}$ Activation of these kinases upregulates and activates NFKB and activator protein-1 (AP-1), ${ }^{49}$ which subsequently (a) activates c-Jun $N$-terminal kinase (JNK) and inhibitor of NFKB kinase- $\beta$ (IKK), (b) transcriptionally upregulates proinflammatory cytokine genes, ${ }^{22}$ and (c) increases the synthesis of acutephase reactants. ${ }^{50-52}$ This molecular cascade reduces the downstream signaling elicited by insulin through dysregulation of the insulin receptor (IR) substrate-1 (IRS-1), the primary molecular target of IR ${ }^{53,54}$ (Figure 2). Concurrently, the ensuing inflammation leads to an enhanced production of reactive oxidant species, further tipping the balance in favor of elevated oxidative stress and NFKB-mediated proinflammatory pathways. ${ }^{5,37,47}$ Because the JNK-AP-1 and

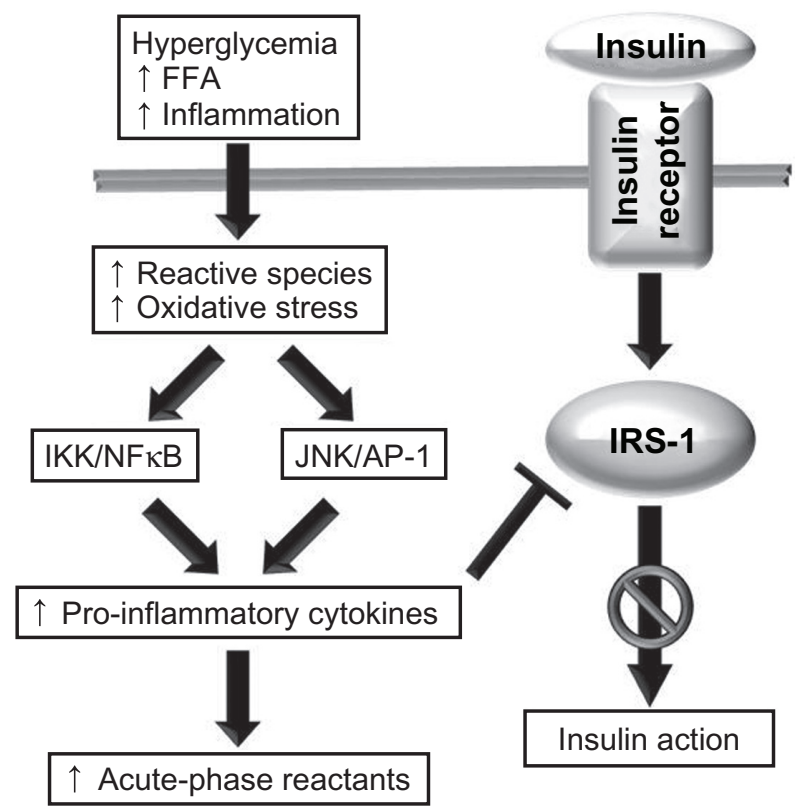

Figure 2 The role of oxidative stress and inflammation in insulin resistance. A number of stimuli, such as hyperglycemia, high levels of circulating free fatty acid (FFA), and chronic inflammation, lead to increases in the production of reactive molecular species, and this in turn may lead to oxidative stress. Oxidants activate the JNK/AP-I and IKK-NFKB axes, leading to an upregulation in the transcription of proinflammatory cytokine genes and increased production of cytokines and acute-phase reactants. Cytokines impair the action of the insulin receptor substrate, resulting in impaired insulin action.
IKK-NFkB axes are the major inflammatory pathways that disrupt insulin signaling, modulating their action with antioxidant or anti-inflammatory factors is believed to improve insulin sensitivity and glucose homeostasis. ${ }^{24}$

A number of studies have highlighted a direct link between oxidative stress and diabetes through the measurement of markers of oxidative stress (eg, plasma and urinary $\mathrm{F}_{2}$-isoprostanes and plasma and tissue levels of nitrotyrosine and superoxide). ${ }^{17,55-59}$ Oxidative stress in diabetes arises from various pathways, including nonenzymatic, enzymatic, and mitochondrial processes. Hyperglycemia modifies the redox balance through the polyol pathway (where glucose is reduced to sorbitol, with subsequent decreases in levels of NADPH and reduced glutathione), activates oxidases, and interferes with the mitochondrial electron transport chain. ${ }^{35,60-63}$ These processes generate by-products that can trigger various signaling cascades, for example activation of protein kinase $\mathrm{C}$ to further increase the synthesis of reactive oxidative species. ${ }^{35,62,64}$ Nonenzymatically, glucose autoxidation generates hydroxyl radical ${ }^{65}$ and leads to the formation of advanced glycation end products that influence the transcription of proinflammatory genes to promote further oxidative stress. ${ }^{63,66}$ In healthy subjects, hyperglycemia has been also associated with oxidative stress, as measured through plasma levels of nitrotyrosine.$^{67}$

Oxidative stress and chronic inflammation are closely linked via positive feedback mechanisms. Both factors are associated with obesity and a range of metabolic syndromes (Figure 3). High circulating FFA levels, which are characteristic of obesity and T2DM, influence oxidative stress via $\beta$-oxidative phos-

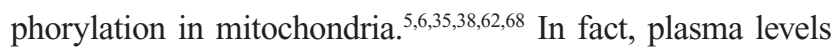

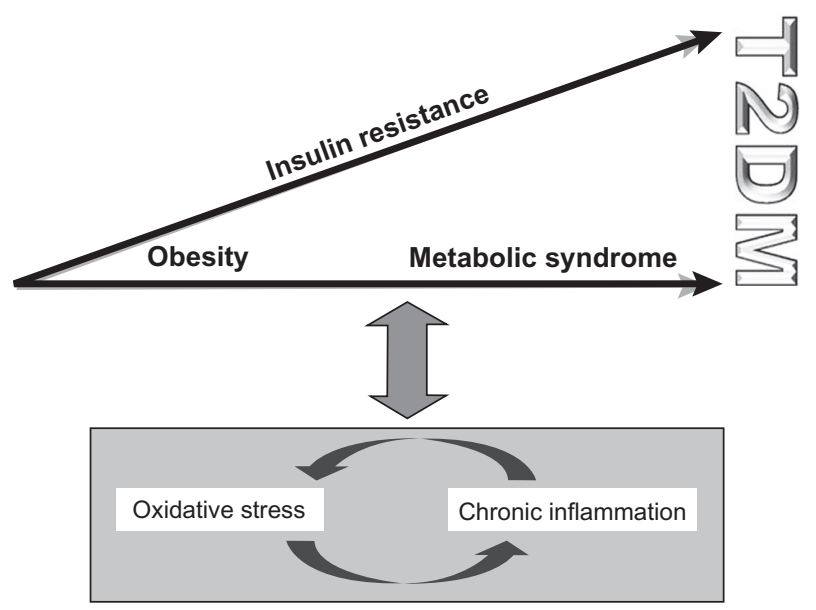

Figure 3 The interaction between oxidative stress, chronic inflammation, and the progression toward T2DM. Oxidative stress and chronic inflammation are closely linked via positive feedback mechanisms and are both associated with obesity and the metabolic syndrome. 
of the antioxidant glutathione have been shown to decrease by FFA infusion. ${ }^{62,69}$ Furthermore, levels of malondialdehyde (MDA), a marker of oxidative stress, and expression of $\mathrm{NF} \kappa \mathrm{B}$ are elevated in insulin-resistant states when hyperglycemia is absent in vascular, adipose, and muscular tissues. ${ }^{62,69,70}$

Reactive species can play a role directly in insulin sensitivity, secretion, and action in both animal and human models. ${ }^{33,71-73}$ For example, nondiabetic rats that were infused with high levels of glucose and administered either of two antioxidants, that is, $\mathrm{N}$-acetylcysteine or taurine, did not develop insulin resistance despite being hyperglycemic, suggesting that oxidative stress may play a role in glucoseinduced insulin resistance and that this effect can be prevented by antioxidative factors. ${ }^{74}$ Oxidative stress has also been noted to coexist with insulin resistance in patients with T2DM, ${ }^{75,76}$ in obese subjects, and at various stages of the metabolic syndrome. ${ }^{10}$ For example, insulin resistance has been noted in obese women with reduced total antioxidant status $^{30}$ and in men with plasma levels of 8-epi-prostaglandin F2 $\alpha$ (PGF2 $\alpha$ ), a marker for lipid peroxidation. ${ }^{31}$ Furthermore, suboptimal concentrations of circulating antioxidants ${ }^{77}$ and elevated levels of several markers of oxidative stress (eg, MDA, homocysteine, and ceruloplasmin) were found in subjects with metabolic syndrome. ${ }^{78}$

The effects of reactive oxidative species can be modified by enzymatic action (eg, superoxide dismutase, thioredoxin, catalase, and glutathione peroxidase $)^{5}$ and/or by nonenzymatic antioxidants, for example, vitamins (A, C, E, and B), folate, glutathione, coenzyme $\mathrm{Q}_{10}$, $\alpha$-lipoic acid (LA), carotenoids, flavonoids, and trace elements $(\mathrm{Cu}, \mathrm{Zn}, \mathrm{Mg}$, and $\mathrm{Se}) .{ }^{17,79}$ Antioxidants often work in synergy with target specific reactive species, ${ }^{79}$ and through their ameliorating effects on oxidative stress, they also attenuate inflammation at the molecular level.

\section{Micronutrients in T2DM: attenuation of oxidative stress and inflammation}

Factors that attenuate oxidative stress and proinflammatory cascades could provide an important public health tool to reduce the burden of chronic diseases linked to these conditions, such as obesity, T2DM, and cardiovascular diseases. A number of reports have evaluated the efficacy of anti-inflammatory and antioxidant pharmaceutical agents on manifestation and outcome of T2DM and cardiovascular disease (see below). For example, studies in animal models and humans have demonstrated that disrupting the IKK $\beta-\mathrm{NF} \kappa \mathrm{B}$ pathway improves obesity-related insulin sensitivity. ${ }^{80}$ Blocking JNK activity in diabetic animals improved systemic glucose homeostasis and insulin sensitivity, ${ }^{81}$ whereas inhibition of IKK by salicylates led to enhanced insulin action. ${ }^{82}$

The major current therapeutic agents to treat T2DM, sulfonylureas, metformin, and insulin-sensitizing glitazones, all have been associated with normalization of circulating inflammation and oxidative markers. ${ }^{12-14,83-85}$ This effect may be mediated, at least partly, by the action of the therapeutic agents on the innate immune system to retain the homeostasis of the oxidative and inflammatory status. Accordingly, glitazones (peroxisome proliferator-activated receptor- $\gamma$ [PPAR- $\gamma$ ] agonists) improved the activities of superoxide dismutase and catalase and glutathione peroxidase in the lung tissue of hyperglycemic rabbits. ${ }^{12,86}$ Treatment of these animals with repaglinide, an antioxidant often used in T2DM treatment, resulted in higher glutathione levels and normalization of nitrotyrosine. ${ }^{83}$ Similarly, several therapeutic agents prescribed in T2DM, such as metformin and sulfonylureas, exhibit antioxidant and anti-inflammatory activity, an effect that may be partially related to their therapeutic efficacy. ${ }^{13,14,84,85}$ These observations provide an additional line of evidence to emphasize that targeting the inflammation-related and oxidation-related pathways can provide a feasible approach in the prevention of T2DM.

Micronutrient and/or trace element supplementation can modify oxidative stress and innate immune-related responses and, subsequently, reduce the burden of a range of chronic conditions. A recent study showed an interdependent and inverse association between total antioxidant capacity of the diet and CRP serum levels in nondiabetic subjects. ${ }^{87}$ This observation suggests the value of using nutritional supplementation to modulate inflammation and oxidative stress in a population-based setting. With respect to T2DM, the consensus of available information suggests that micronutrient intake modulates oxidative stress and the innate immune system ${ }^{88,89}$ to subsequently influence the predisposition to (and prevention of) disease. ${ }^{88,90,91}$ Therefore, it is possible to monitor the outcome of nutritional supplementation simply by evaluating its modifying action on the levels of inflammatory biomarkers.

Many micronutrients exhibit well-characterized antiinflammatory or immunomodulatory functions (see below). Vitamins (eg, D, E, and C) and trace elements (eg, Se, Zn, $\mathrm{Cu}$, and $\mathrm{Fe}$ ) are known to improve the overall function of the immune system, prevent excessive expression of inflammatory cytokines, and increase the 'oxidative burst' potential of macrophages. ${ }^{88}$ Natural health products (NHPs) that contain pertinent micronutrients (eg, so-called adaptogenic medicinal plants) or modulate the innate immune response (eg, omega-3 fatty acids and probiotics) can also be explored 
for their preventive efficacy in chronic diseases despite their controversial benefits. ${ }^{92}$ Dietary intake of omega-3 fatty acids is known to inhibit the production of proinflammatory cytokines, including IL-1 $\beta$ and TNF- $\alpha .{ }^{93}$ Furthermore, supplementation with Allium sativum (garlic), Curcuma longa (long turmeric), Panax quinquefolius (American ginseng), and Panax ginseng (Asian ginseng), selected candidates of a large group of antioxidant, anti-inflammatory, and adaptogenic plants, was reported to downregulate the oxidative stress and the synthesis of proinflammatory cytokines, effects related to their overall action on enhancing the innate immune response. ${ }^{94-98}$ Similarly, some trace elements (eg, Zn) could play a role in preventing T2DM by regulating dysglycemia and decreasing insulin insensitivity. For example, it is well known that T2DM can be accompanied by a slow loss of intracellular Zn and hyperzincuria. ${ }^{99}$ Supplementation with $\mathrm{Zn}$, therefore, has been shown to lower oxidative stressrelated byproducts and to attenuate the synthesis of TNF- $\alpha$ and IL-1 $\beta{ }^{100-103}$ This observation may substantiate an antidiabetes action for $\mathrm{Zn}$, and perhaps other trace elements, via its antioxidative and anti-inflammatory characteristics.

Exploring the possibility that supplementation with selected micronutrients, trace elements, and/or NHPs can attenuate inflammation and, subsequently, delay the onset of T2DM should be considered alongside existing public health practices to reduce the rising incidence of the disease. Here, we review the evidence for immunomodulatory, antioxidant, and anti-inflammatory effects of specific micronutrients, namely vitamins $\mathrm{D}, \mathrm{C}$, and $\mathrm{E}$, and their overall effect on the prevention of T2DM and the related metabolic syndromes.

\section{Vitamin D}

The role of vitamin $\mathrm{D}$ in calcium and phosphorous homeostasis and bone metabolism is well understood. However, more recently, vitamin $\mathrm{D}$ and calcium homeostasis have also been linked to a number of conditions, such as neuromuscular function, cancer, and a wide range of chronic diseases, including autoimmune diseases, atherosclerosis, obesity, cardiovascular diseases, diabetes, and associated conditions such as the metabolic syndrome and insulin resistance. , $^{8,91,104,105}$ In T2DM, the role of vitamin D was suggested from the presence of vitamin D receptors (VDR) in the pancreatic $\beta$-islet cells. ${ }^{106}$ In these cells, the biologically active metabolite of vitamin D (ie, 1,25-dihydroxy-vitamin $\left.\mathrm{D} ; 1,25(\mathrm{OH})_{2} \mathrm{D}\right)^{88}$ enhances insulin production and secretion via its action on the VDR. ${ }^{106}$ Indeed, the presence of vitamin D binding protein (DBP), a major predictor of serum levels of $25(\mathrm{OH})$ $\mathrm{D}$ and response to vitamin D supplementation, ${ }^{107,108}$ and VDR initiated several studies demonstrating a relationship between single-nucleotide polymorphisms (SNPs) in the genes regulating VDR and DBP and glucose intolerance and insulin secretion. ${ }^{109-111}$ This further supports a role for vitamin D in T2DM and may explain the reduced overall risk of the disease in subjects who ingest $>800 \mathrm{IU} /$ day of vitamin D. ${ }^{91,112}$ However, an alternative, perhaps related, explanation was recently proposed for the role of vitamin $\mathrm{D}$ in the prevention of T2DM based on its potent immunomodulatory functions. ${ }^{113-115}$ $1,25(\mathrm{OH})_{2} \mathrm{D}$ modulates the production of the immunostimulatory IL-12 and the immunosuppressive IL-10, ${ }^{116}$ and VDRs are present in most types of immune cells. ${ }^{117}$ In this respect, supplementation with vitamin $\mathrm{D}^{118}$ or its bioactive form, $1,25(\mathrm{OH})_{2} \mathrm{D},{ }^{88}$ improved insulin sensitivity by preventing the excessive synthesis of inflammatory cytokines. This effect of vitamin D on cytokine synthesis is due to its interaction with vitamin D response elements present in the promoter region of cytokine-encoding genes. This interaction downregulates the transcriptional activities of cytokine genes and attenuates the synthesis of the corresponding proteins. ${ }^{118}$ Vitamin D also deactivates $\mathrm{NF} \kappa \mathrm{B}$, which transcriptionally regulates the proinflammatory cytokine-encoding genes. ${ }^{119}$ Downregulating the expression of NFKB and downstream cytokine genes inhibits $\beta$-cell apoptosis and promotes their survival. ${ }^{118}$

As reviewed by Pittas et al, ${ }^{91,120}$ a number of crosssectional studies in both healthy and diabetic cohorts have shown an inverse association between serum 25(OH)D and glycemic status measures such as fasting plasma glucose, oral glucose tolerance tests, hemoglobin $\mathrm{A}_{1 \mathrm{c}}\left(\mathrm{HbA}_{1 \mathrm{c}}\right)$, and insulin resistance as measured by the homeostatic model assessment (HOMA-R), as well as the metabolic syndrome. ${ }^{3,121-125}$ For example, data from the National Health and Nutrition Examination Survey showed an inverse, dose-dependent association between serum $25(\mathrm{OH}) \mathrm{D}$ and diabetes prevalence in non-Hispanic whites and Mexican Americans, but not in non-Hispanic blacks. ${ }^{122,125}$ The same inverse trend was observed between serum $25(\mathrm{OH}) \mathrm{D}$ and insulin resistance as measured by HOMA-R, but there was no correlation between serum levels of vitamin $\mathrm{D}$ and $\beta$-cell function, as measured by HOMA- $\beta .{ }^{122,125}$ Data from the same cohort also showed an inverse association between serum $25(\mathrm{OH}) \mathrm{D}$ and prevalence of the metabolic syndrome. ${ }^{122}$

In prospective studies, dietary vitamin $\mathrm{D}$ intake has been associated with incidence of T2DM. For example, data from the Women's Health Study showed that among middle-aged and older women, taking $>511 \mathrm{IU} /$ day of vitamin $\mathrm{D}$ reduced the risk of developing T2DM compared to ingesting 159 IU/day. ${ }^{126}$ Furthermore, data from the Nurses Health Study also found a 
significant inverse correlation between total vitamin D intake and T2DM risk, even after adjusting for BMI, age, and nondietary covariates. ${ }^{112}$ Intervention studies have shown conflicting results about the effect of vitamin D on T2DM incidence. One study reported that supplementation with $1,25(\mathrm{OH})_{2} \mathrm{D}$ for 1 week did not affect fasting glucose or insulin sensitivity in 18 young, healthy men. ${ }^{127}$ Another study found that among 14 T2DM patients, supplementing with $80 \mathrm{IU} /$ day of $1,25(\mathrm{OH})_{2} \mathrm{D}$ ameliorated insulin secretion but did not improve glucose tolerance after a 75-g oral load. ${ }^{128}$ Yet another study showed that among 65 middle-aged men who had IGT or mild T2DM and adequate serum vitamin $\mathrm{D}$ levels at baseline, supplementation with $30 \mathrm{IU} /$ day of $1,25(\mathrm{OH})_{2} \mathrm{D}$ for 3 months affected neither fasting nor stimulated glucose tolerance. ${ }^{129}$ However, in a crossover design, 20 diabetics with inadequate vitamin D serum levels who were given $40 \mathrm{IU} /$ day of $1,25(\mathrm{OH})_{2} \mathrm{D}$ for 4 days had improved insulin secretion, but showed no changes in fasting or stimulated glucose or insulin concentrations. ${ }^{130}$ Although the short duration of this crossover trial may account for the lack of a significant overall effect, the results suggest that improving vitamin D status can modulate factors associated with the development and progression of T2DM.

The data from a 2-year-long trial designed to assess the effects of vitamin $\mathrm{D}$ or $1,25(\mathrm{OH})_{2} \mathrm{D}$ supplementation on bone health in nondiabetic postmenopausal women were analyzed a posteriori and found no significant effect on fasting glucose levels. ${ }^{131}$ A post hoc analysis of data from a 3-year-long trial for bone health showed that daily supplementation with 700 IU of vitamin $\mathrm{D}_{3}$ and $500 \mathrm{mg}$ of calcium citrate malate did not change blood glucose levels or insulin resistance in elderly adults with normal glucose tolerance. These measures, however, were significantly improved in subjects with IGT at baseline. ${ }^{90}$ In this trial, the effect of fasting glucose levels in the high-risk group (ie, IGT) was similar to that observed in the Diabetes Prevention Program after either an intensive lifestyle intervention or metformin treatment. ${ }^{132}$ Another recent randomized, controlled trial found that daily supplementation with $400 \mathrm{IU}$ of vitamin $\mathrm{D}_{3}$ for 6 months in insulin-resistant, nondiabetic, vitamin D-deficient South Asian women living in New Zealand resulted in improved insulin resistance and sensitivity. ${ }^{133}$ Taken together, the available information warrants exploring the possibility that vitamin D, either alone or in combination with calcium supplementation, can be employed in developing population-based strategies for T2DM prevention and control.

\section{Vitamin C}

Vitamin C (ascorbic acid or ascorbate) is the primary hydrophilic antioxidant found in human plasma. ${ }^{134}$
Absorption of vitamin $\mathrm{C}$ occurs in the small intestine via active transport through the sodium-dependent vitamin $\mathrm{C}$ transporter type 1 (SVCT1). SVCT1 also appears in the renal proximal tubules, where it reabsorbs filtered ascorbate and is expressed throughout the body. ${ }^{135}$ Circulating concentrations of ascorbate in blood are considered adequate if it is at least $28 \mu \mathrm{M}$, but they are considerably higher in most cells due to active transport by SVCT2. The daily recommended dietary allowance for vitamin $\mathrm{C}$ is $75 \mathrm{mg}$ for women and $90 \mathrm{mg}$ for men, with an additional $35 \mathrm{mg}$ for smokers due to the higher metabolic turnover of the vitamin in this group compared to nonsmokers. ${ }^{37}$ Ascorbate appears in the urine at intakes of roughly $60 \mathrm{mg} /$ day. However, in a depletion/repletion study in healthy young women, ascorbate plasma and white blood cell concentrations saturated at intakes of $200 \mathrm{mg}$ /day or higher. ${ }^{136}$ These results suggest that for some individuals, the current dietary recommendations may not provide tissue-saturating ascorbate concentrations. ${ }^{135}$ Recent epidemiologic findings suggest that serum ascorbic acid deficiency may be relatively common. For example, a recent cross-sectional survey of healthy young adults of the Toronto Nutrigenomics and Health (TNH) Study reported that one out of seven individuals is deficient in serum ascorbic acid. ${ }^{137}$

Vitamin $\mathrm{C}$ has an important role in immune function and various oxidative/inflammatory processes, such as scavenging ROS and RNS, preventing the initiation of chain reactions that lead to protein glycation, ${ }^{37,40}$ and protecting against lipid peroxidation..$^{37,138}$ The oxidized products of vitamin C, ascorbyl radical and dehydroascorbic acid, are easily regenerated to ascorbic acid by glutathione, NADH, or NADPH. ${ }^{37}$ In addition, ascorbate can recycle vitamin $\mathrm{E}$ and glutathione back from their oxidized forms. ${ }^{37,135}$ For this reason, there has been interest in determining whether vitamin $\mathrm{C}$ might be used as a therapeutic agent against the oxidative stress and subsequent inflammation associated with T2DM.

A variety of epidemiologic studies have assessed the effect of vitamin $\mathrm{C}$ on biomarkers of oxidation, inflammation, and/or T2DM risk. ${ }^{134,139-144}$ A large cross-sectional evaluation of healthy elderly men from the British Regional Heart Study reported that plasma vitamin $C$, dietary vitamin $C$, and fruit intake were inversely correlated with serum CRP and tissue plasminogen activator (tPA), a biomarker of endothelial dysfunction. ${ }^{134}$ However, only plasma vitamin $\mathrm{C}$ was inversely associated with fibrinogen levels. ${ }^{134}$ Another cross-sectional study of adolescents aged 13-17 found inverse associations between intake of fruit, vegetables, legumes, and vitamin $\mathrm{C}$ and urinary $\mathrm{F}_{2}$-isoprostane, CRP, and IL- $6 .{ }^{145}$ A recent cross-sectional evaluation of healthy 
young adults from the TNH Study demonstrated that serum ascorbic acid deficiency is associated with elevated CRP and other factors related to the metabolic syndrome such as waist circumference, BMI, and blood pressure. ${ }^{137}$ Finally, the European Prospective Investigation of Cancer-Norfolk Prospective Study examined the association between fruit and vegetable intake and plasma levels of vitamin $C$ and risk of T2DM. During a 12-year follow-up, 735 incident cases of diabetes were identified among nearly 21,000 participants. A significant inverse association was found between plasma levels of vitamin $\mathrm{C}$ and risk of diabetes (odds ratio $[\mathrm{OR}]=0.38,95 \%$ confidence interval $[\mathrm{CI}]: 0.28-0.52)$. In the same study, a similar association was observed between fruit and vegetable intake and T2DM risk $(\mathrm{OR}=0.78,95 \%$ CI: $0.60-1.00){ }^{41}$

Despite epidemiologic findings generally pointing toward an association between increased vitamin $\mathrm{C}$ and reduced oxidation and inflammation, intervention trials assessing the effect of vitamin $\mathrm{C}$ supplementation on various markers of T2DM have yielded inconsistent results. One randomized, crossover, double-blind intervention trial reported no improvement in fasting plasma glucose and no significant differences in levels of CRP, IL-6, IL-1 receptor agonist, or oxidized low-density lipoprotein (LDL) after supplementation with $3000 \mathrm{mg} /$ day of vitamin C for 2 weeks in a group of 20 T2DM patients, compared to baseline levels. ${ }^{146}$ Chen and colleagues performed a randomized, controlled, double-blind intervention on a group of 32 diabetic subjects with inadequate levels of vitamin $C$ and found no significant changes in either fasting glucose or fasting insulin after intake of $800 \mathrm{mg} /$ day of vitamin C for 4 weeks. ${ }^{147}$ Furthermore, Tousoulis et al reported that treatment with $2000 \mathrm{mg} /$ day for 4 weeks had no effect on levels of CRP, IL-6, TNF- $\alpha$, or soluble vascular cell adhesion molecule-1 in 13 T2DM patients. ${ }^{148}$

On the other hand, Wang and colleagues showed that the red blood cell sorbitol/plasma glucose ratio was reduced after supplementation with $1000 \mathrm{mg}$ /day vitamin C for 2 weeks in a group of eight diabetics, although no differences were found in fasting plasma glucose. ${ }^{42}$ Because sorbitol is a product of the pro-oxidative polyol pathway, this observation may suggest an inhibition of the polyol pathway by vitamin $\mathrm{C}$ among subjects with diabetes. Another study has shown that daily intake of ascorbic acid at $2000 \mathrm{mg} /$ day improved fasting plasma glucose, $\mathrm{HbA}_{1 \mathrm{c}}$, cholesterol levels, and triglycerides in 56 diabetics. ${ }^{149}$ In agreement, Paolisso et al found that $1000 \mathrm{mg} /$ day of vitamin $\mathrm{C}$ for 4 months improved LDL and total cholesterol, fasting plasma insulin, and free radicals, although it did not affect triglycerides or HDL levels in a group of 40 diabetics. ${ }^{43}$
Overall, it remains unclear whether vitamin $\mathrm{C}$ intake has an effect on factors related to T2DM. Although the epidemiologic evidence suggests that vitamin C, whether as a supplement or as part of a diet rich in fruits and vegetables, beneficially affects inflammatory markers and disease risk, the results of intervention trials in T2DM are conflicting. Small sample sizes, genetic variation, short intervention duration, insufficient dosage, and disease status of the assessed cohorts may account for the lack of effect and the inconsistent outcomes observed in intervention studies. However, it is also possible that the status of vitamin $\mathrm{C}$ deficiency is a result of the oxidative and proinflammatory challenges associated with T2DM, rather than a determinant of disease pathogenesis. Therefore, further research and long-term prospective studies are needed to elucidate the role of vitamin $\mathrm{C}$ as a modulator of inflammation and T2DM risk and to evaluate its potential role as a preventive agent at a population level.

\section{Vitamin E}

Vitamin E occurs as four common types: $\alpha$ tocopherol, $\beta$ tocopherol, $\gamma$ tocopherol, and $\delta$ tocopherol, and these differences in chemical structure have different molecular functions and impacts. ${ }^{40} \alpha$ Tocopherol is the major form recognized by the $\alpha$ tocopherol transfer protein in the liver and is, therefore, incorporated into very low-density lipoprotein, whereas $\gamma$ tocopherol is metabolized and thus not retained. This results in much higher concentrations of $\alpha$ than $\gamma$ tocopherol in the body ${ }^{37}$ Although vitamin E supplements consist primarily of $\alpha$ tocopherol, $\gamma$ tocopherol is the main dietary source of the vitamin, as it is found in various vegetable oils, seeds, and nuts. ${ }^{37}$ Vitamin E intake increases the rate of lymphocyte proliferation by enhancing the ability of $\mathrm{T}$ cells to undergo cell division cycles. ${ }^{150}$ Its anti-inflammatory action, however, has been substantiated from observations demonstrating its ability to modulate the expression of the IL- 2 and IL-4 genes and the IL-1 receptor antagonist following supplementation in animal models. ${ }^{151}$ In T2DM patients, vitamin E reduced the serum levels of IL- $1 \beta$, IL-6, TNF- $\alpha$, PAI- 1 , and CRP. ${ }^{15}$

The anti-inflammatory actions of vitamin $\mathrm{E}$ are believed to be related to its post-transcriptional inhibitory action on 5 -lipoxygenase, ${ }^{152}$ a member of the lipoxygenase family of enzymes involved in the synthesis of the inflammatory prostaglandins. Additionally, vitamin E downregulates $\mathrm{NF} \kappa \mathrm{B}$ and exerts potent lipophilic antioxidant effect on internal and external cell membranes as well as plasma lipoproteins, notably LDL. ${ }^{15}$ Indeed, studies in both animal models and humans have demonstrated that vitamin $\mathrm{E}$ 
intake blocks LDL lipid peroxidation, prevents the oxidative stress linked to T2DM-associated abnormal metabolic patterns (hyperglycemia, dyslipidemia, and elevated levels of FFAs), and, subsequently, attenuates cytokine gene expression. ${ }^{15,62,151,153}$

A number of epidemiological studies demonstrated an inverse association between vitamin $\mathrm{E}$ and markers of oxidation, inflammation, and T2DM incidence. ${ }^{154-156}$ For example, a 4-year prospective assessment of 944 nondiabetic Finnish men found that below-median plasma vitamin E levels were associated with a 3.9-fold higher relative risk of diabetes (95\% CI: 1.8-8.6). ${ }^{154}$ Another case-control study ( $n=106$ cases, 201 controls) reported an inverse association between vitamin E serum levels and T2DM status, although the association became statistically insignificant after adjusting for cardiovascular disease risk factors (ie, serum cholesterol, obesity, smoking, and hypertension). ${ }^{155}$ The Insulin Resistance Atherosclerosis Study, a 5-year prospective study of nearly 900 nondiabetic adults, found that plasma concentrations of $\alpha$ tocopherol offered a significant protective effect against T2DM $(\mathrm{OR}=0.12,95 \%$ CI: $0.02-0.68) .{ }^{156}$ In contrast, various epidemiologic studies and intervention trials (see below) reported inconsistent findings. For example, supplementation with $750 \mathrm{IU} /$ day of mixed tocopherols for 6 weeks reduced plasma but not urinary $\mathrm{F}_{2}$-isoprostanes, a marker of oxidative stress in vivo, in two different studies on subjects with T2DM. ${ }^{157,158}$ This level of supplementation did not alter the serum concentration of CRP, IL-6, TNF- $\alpha$, or MCP-1 in one study ${ }^{158}$ and was associated with increased blood pressure and heart rate in another trial. ${ }^{157}$

Data from the Women's Health Study, assessing women health at baseline, demonstrated that supplementation with 600 IU of $\alpha$ tocopherol for 10 years on alternate days had no significant benefit for T2DM. ${ }^{159}$ However, in another trial of 15 diabetics and 10 control individuals, 4 months of daily supplementation with 1350 IU of $\alpha$ tocopherol significantly improved plasma glucose levels, triglycerides, total cholesterol levels, $\mathrm{LDL}$, and $\mathrm{HbA}_{1 \mathrm{c}}$, but did not improve the response of $\beta$ cells to glucose or FFAs. ${ }^{44}$ In a trial involving 34 Mexican diabetic women, daily supplementation with 800 IU of $\alpha$ tocopherol for 6 weeks improved total antioxidant status and reduced MDA levels, but had no effect on serum glucose, lipids, or $\mathrm{HbA}_{1 \mathrm{c}}$ levels. ${ }^{160}$ Daily supplementation with 1600 IU of $\alpha$ tocopherol for 10 weeks in a group of 21 diabetic men had no effect on $\mathrm{HbA}_{1 \mathrm{c}}$, fasting blood glucose, or glycated plasma protein concentrations, but had a beneficial effect on LDL oxidation. ${ }^{161}$
Despite these conflicting findings, a recent study evaluated the effects of daily supplementation of a combination of vitamin C (20,000 IU) and vitamin E (400 IU) for 4 weeks on insulin sensitivity in untrained $(n=19)$ and trained $(n=20)$ healthy young men. ${ }^{162}$ The study concluded that such a regimen may preclude the exercise-induced amelioration of insulin resistance in humans. ${ }^{162}$ This may relate to the source of vitamin E used, that is, $\alpha, \beta, \gamma$, or $\delta$ tocopherols. ${ }^{163}$ Indeed, one study assessed the differences between $\alpha$ and $\gamma$ tocopherols on factors related to the metabolic syndrome. ${ }^{164}$ Subjects with the metabolic syndrome were administered either form of vitamin $\mathrm{E}$ or an equal mixture of the two at doses of $1200 \mathrm{IU} /$ day for 6 weeks. Plasma levels of IL- $1 \beta$, TNF- $\alpha$, IL-6, CRP, and markers of oxidative stress were measured. Serum levels of CRP were decreased after supplementation with both $\alpha$ and $\gamma$ tocopherols, and only the combined treatment yielded a significant lowering effect on the inflammatory markers. TNF- $\alpha$ decreased with $\alpha$ and mixed tocopherols, but neither IL- $1 \beta$ nor IL- 6 were affected by any treatment regimen. Markers of oxidative stress, such as MDA and lipid peroxides, were significantly reduced with all treatments. ${ }^{164}$ These results suggest that supplementation with combined $\alpha$ and $\gamma$ tocopherols may be more beneficial in reducing oxidative stress and inflammation than either isoform alone. Furthermore, given the role of vitamin $\mathrm{C}$ in regeneration of oxidized vitamin $\mathrm{E}$ (see above), combined vitamin $\mathrm{C}$ and vitamin $\mathrm{E}$ may be more effective than administering either micronutrient on its own. For example, 13 elderly men with impaired fasting glucose were given a daily combination of $1000 \mathrm{mg} \alpha$ tocopherol and $1000 \mathrm{IU}$ vitamin $\mathrm{C}$ for 4 weeks. The combined supplement yielded significant reductions in levels of fasting plasma insulin, glucose, TNF- $\alpha$, and 8-isoprostane. ${ }^{45}$

In general, inconsistent results from studies evaluating the effect of vitamin $\mathrm{E}$ on inflammation, oxidation, and T2DM risk may result partly from genetic differences between individuals that could lead to variations in response to micronutrient exposure. For example, SNPs in the TNF- $\alpha$ gene (eg, $-308 \mathrm{G}>\mathrm{A}$ ) affected the inflammatory response of elderly individuals to supplementation with $273 \mathrm{IU} /$ day of $\alpha$ tocopherol for 1 year. ${ }^{165}$ When carriers of the A allele received vitamin E, they had lower TNF- $\alpha$ synthesis upon exposure to lipopolysaccharides compared to their nonsupplemented counterparts. Because the A allele has been previously associated with higher TNF- $\alpha$ levels, it was concluded that the anti-inflammatory effects of vitamin $\mathrm{E}$ are specific to those who are genetically predisposed to develop inflammatory responses upon exposure to stimuli. ${ }^{165}$ This observation is 
critical in identifying subjects of the general population who will benefit more from vitamin E supplementation based on their genetic predisposition to disease-related factors.

\section{Conclusion and future directions}

Introducing novel and effective prevention strategies in a public health setting necessitates considering approaches with the least (if any) side effects and the maximal preventive efficacy and outcome. In this context, applying nutritional intervention to attenuate inflammation and oxidative stress would be a feasible public health strategy for prevention of T2DM. This approach should be explored in prediabetic subjects and the outcome should be compared to the effect(s) of modifying current practices, such as lifestyle change, dietary intervention, and exercise. The effectiveness of lifestyle-change intervention programs for prediabetes also shows a promising effect on the reduction of overall incidence of T2DM or its complications, and it can be implemented in general clinical practice. ${ }^{166} \mathrm{~A}$ lifestyle-change program including increased exercise and change in diet (either by reduction in glycemic load or reduced-fat diet) demonstrated a significant difference between control and intervention groups in markers for risk of progression to T2DM including weight, BMI, and waist circumference. ${ }^{166}$ In general, current approaches for the prevention of T2DM have been shown to be effective in delaying or preventing the progression from prediabetes to diabetes. ${ }^{167}$ In patients with insulin resistance, these practices are known to improve insulin sensitivity and the overall predisposition to T2DM. ${ }^{168}$ On the other hand, increasing intake of vitamin D to $>800$ IU daily along with $1200 \mathrm{mg}$ of calcium was reported to reduce the risk of developing T2DM by $33 \% .{ }^{91}$ In agreement, healthy older adults with impaired fasting glucose showed significant improvement in attenuating the glycemic response and insulin resistance when they increased their intake of vitamin D by $700 \mathrm{IU} /$ day and calcium by $500 \mathrm{mg} /$ day for 3 years. ${ }^{112}$

It seems reasonable, therefore, to suggest that the two preventive approaches for T2DM, that is micronutrient supplementation and lifestyle change, may be combined into a single successful intervention program. This strategy may be more efficient in reducing the burden of the disease in the general population and in vulnerable subpopulations than when a single approach is proposed. Moreover, such a combined approach may be introduced into the general practice setting and to the general population with low expenditure and minimal side effects. ${ }^{8}$

Overall, the current state of knowledge warrants further study into the extent to which micronutrients can modify the association between markers of inflammation and oxidative stress and early stages of T2DM. There is evidence supporting the idea that vitamin supplementation can modify the genotype-phenotype association within the innate immune response (ie, the proinflammatory and inflammatory markers) and that it has an ameliorating effect on oxidative stress and the subsequent proinflammatory signaling. This proposition may provide the mechanism by which nutritional factors prevent or delay disease development and can be introduced into the general population, as well as susceptible subpopulations. In relation to the current preventive approaches for T2DM, for example, lifestyle changes, exercise, and dietary intervention, exploring the efficacy of micronutrient supplementation on attenuating oxidative stress, the innate immune response, and the ensuing inflammation and evaluating the outcome of this strategy on T2DM incidence may be assessed through a series of prospective population-based studies, first, to determine the feasibility and effectiveness of this protocol; second, to validate and evaluate this strategy and ensure replication of results; and, third, to monitor the outcome to quantify the overall preventive response in comparison with the current approaches. As reviewed by Willcox et al, ${ }^{169}$ study design is an issue to consider when assessing the efficacy of antioxidants in reducing the risk of developing cardiometabolic diseases. Intervention trials should be designed with sufficient power to measure T2DM as a primary, rather than a secondary, outcome. Furthermore, these studies should investigate the effects of antioxidant vitamins and trace elements in representative populations so that the results are applicable to high-risk groups, and they should take into account genetic variation accounting for interindividual differences in response to supplementation. Consideration should be also given to the antioxidants given in specific studies, as different antioxidants exert their effects through different mechanisms. ${ }^{169}$

\section{Disclosure}

The authors report no conflicts of interest in this work.

\section{References}

1. Zimmet P, Alberti KG, Shaw J. Global and societal implications of the diabetes epidemic. Nature. 2001;414(6865):782-787.

2. Wild S, Roglic G, Green A, Sicree R, King H. Global prevalence of diabetes: estimates for the year 2000 and projection for 2030. Diabetes Care. 2004;27(5):1047-1053.

3. Mokdad AH, Bowman BA, Ford ES, Vinicor F, Marks JS, Koplan JP. The continuing epidemics of obesity and diabetes in the United States. JAMA. 2001;286(10):1195-1200.

4. Venkataraman R, Nanda NC, Baweja G, Parikh N, Bhatia V. Prevalence of diabetes mellitus and related conditions in Asian Indians living in the United States. Am J Cardiol. 2004;94(7):977-980. 
5. Lamb RE, Goldstein BJ. Modulating an oxidative-inflammatory cascade: potential new treatment strategy for improving glucose metabolism, insulin resistance, and vascular function. Int J Clin Pract. 2008;62(7):1087-1095.

6. Savage DB, Petersen KF, Shulman GI. Mechanisms of insulin resistance in humans and possible links with inflammation. Hypertension. 2005; 45(5):828-833.

7. Stumvoll M, Goldstein BJ, van Haeften TW. Type 2 diabetes: principles of pathogenesis and therapy. Lancet. 2005;365(9467): 1333-1346

8. Badawi A, Klip A, Haddad P, et al. Type 2 diabetes mellitus and inflammation: prospects for biomarkers of risk and nutritional intervention. Diabetes Metab Syndr Obes. 2010;3:173-186.

9. Pickup JC. Inflammation and activate innate immunity in the pathogenesis of type 2 diabetes. Diabetes Care. 2004;27(3): 813-823.

10. Evans JL, Maddux BA, Goldfine ID. The molecular basis for oxidative stress-induced insulin resistance. Antioxid Redox Signal. 2005;7(7-8): 1040-1052.

11. Alberti KG. Treating type 2 diabetes-today's targets, tomorrow's goals. Diabetes Obes Metab. 2001;3 Suppl 1:S3-S10.

12. Dandona P, Aljada A, Bandyopadhyay A. Inflammation: the link between insulin resistance, obesity and diabetes. Trends Immunol. 2004;25(1):4-7.

13. Dandona P, Aljada A. A rational approach to pathogenesis and treatment of type 2 diabetes mellitus, insulin resistance, inflammation, and atherosclerosis. Am J Cardiol. 2002;90(5A):27G-33G.

14. Dandona P, Aljada A, Chaudhuri A, Bandyopadhyay A. The potential influence of inflammation and insulin resistance on the pathogenesis and treatment of atherosclerosis-related complications in type 2 diabetes. J Clin Endocrinol Metab. 2003;88(6):2422-2429.

15. Singh U, Jialal I. Anti-inflammatory effects of alpha-tocopherol. Ann NY Acad Sci. 2004;1031:195-203.

16. Isharwal S, Misra A, Wasir JS, Nigam P. Diet and insulin resistance: a review and Asian Indian perspective. Indian J Med Res. 2009;129(5): 485-499.

17. Johansen JS, Harris AK, Rychly DJ, Ergul A. Oxidative stress and the use of antioxidants in diabetes: linking basic science to clinical practice. Cardiovasc Diabetol. 2005;4(1):5.

18. Houstis N, Rosen ED, Lander ES. Reactive oxygen species have a causal role in multiple forms of insulin resistance. Nature. 2006;440(7086): 944-948.

19. Pickup JC, Mattock MB, Chusney GD, Burt D. NIDDM as a disease of the innate immune system: association of acute-phase reactants and interleukin-6 with metabolic syndrome X. Diabetologia. 1997;40(11): 1286-1292.

20. Pickup JC, Crook MA. Is type II diabetes mellitus a disease of the innate immune system? Diabetologia. 1998;41(10):1241-1248.

21. Cone JB. Inflammation. Am J Surg. 2001;182(6):558-562.

22. Medzhitov R, Janeway C Jr. Innate immunity. N Engl J Med. 2000; 343(5):338-344

23. Bilan PJ, Samokhvalov V, Koshkina A, Schertzer JD, Samaan MC, Klip A. Direct and macrophage-mediated actions of fatty acids causing insulin resistance in muscle cells. Arch Physiol Biochem. 2009;115(4): 176-190.

24. Hotamisligil GS. Inflammation and metabolic disorders. Nature. 2006; 444(7121):860-867.

25. Hotamisligil GS, Arner P, Caro JF, Atkinson RL, Spiegelman BM. Increased adipose tissue expression of tumor necrosis factor-alpha in human obesity and insulin resistance. $J$ Clin Invest. 1995;95(5): 2409-2415.

26. Fernandez-Real JM, Pickup JC. Innate immunity, insulin resistance and type 2 diabetes. Trends Endocrinol Metab. 2008;19(1): $10-16$.

27. Fridlyand LE, Philipson LH. Reactive species and early manifestation of insulin resistance in type 2 diabetes. Diabetes Obes Metab. 2006; $8(2): 136-145$.
28. Rosen P, Nawroth PP, King G, Moller W, Tritschler HJ, Packer L. The role of oxidative stress in the onset and progression of diabetes and its complications: a summary of a Congress Series sponsored by UNESCO-MCBN, the American Diabetes Association and the German Diabetes Society. Diabetes Metab Res Rev. 2001;17(3):189-212.

29. West IC. Radicals and oxidative stress in diabetes. Diabet Med. 2000; 17(3):171-180

30. Fenkci V, Fenkci S, Yilmazer M, Serteser M. Decreased total antioxidant status and increased oxidative stress in women with polycystic ovary syndrome may contribute to the risk of cardiovascular disease. Fertil Steril. 2003;80(1):123-127.

31. Urakawa H, Katsuki A, Sumida Y, et al. Oxidative stress is associated with adiposity and insulin resistance in men. J Clin Endocrinol Metab. 2003;88(10):4673-4676.

32. Brownlee M. The pathobiology of diabetic complications: a unifying mechanism. Diabetes. 2005;54(6):1615-1625.

33. Evans JL, Goldfine ID, Maddux BA, Grodsky GM. Are oxidative stress-activated signaling pathways mediators of insulin resistance and beta-cell dysfunction? Diabetes. 2003;52(1):1-8.

34. Facchini FS, Hua NW, Reaven GM, Stoohs RA. Hyperinsulinemia: the missing link among oxidative stress and age-related diseases? Free Radic Biol Med. 2000;29(12):1302-1306.

35. Inoguchi T, Li P, Umeda F, et al. High glucose level and free fatty acid stimulate reactive oxygen species production through protein kinase C-dependent activation of NAD(P)H oxidase in cultured vascular cells. Diabetes. 2000;49(11):1939-1945.

36. Tripathy D, Mohanty P, Dhindsa S, et al. Elevation of free fatty acids induces inflammation and impairs vascular reactivity in healthy subjects. Diabetes. 2003;52(12):2882-2887.

37. Calder PC, Albers R, Antoine JM, et al. Inflammatory disease processes and interactions with nutrition. Br J Nutr. 2009;101 Suppl 1:S1-S45.

38. Evans JL, Goldfine ID, Maddux BA, Grodsky GM. Oxidative stress and stress-activated signaling pathways: a unifying hypothesis of type 2 diabetes. Endocr Rev. 2002;23(5):599-622.

39. Esposito K, Nappo F, Marfella R, et al. Inflammatory cytokine concentrations are acutely increased by hyperglycemia in humans: role of oxidative stress. Circulation. 2002;106(16):2067-2072.

40. Bartlett HE, Eperjesi F. Nutritional supplementation for type 2 diabetes: a systematic review. Ophthalmic Physiol Opt. 2008;28(6):503-523.

41. Harding AH, Wareham NJ, Bingham SA, et al. Plasma vitamin C level, fruit and vegetable consumption, and the risk of new-onset type 2 diabetes mellitus: the European prospective investigation of cancer-Norfolk prospective study. Arch Intern Med. 2008;168(14):1493-1499.

42. Wang H, Zhang ZB, Wen RR, Chen JW. Experimental and clinical studies on the reduction of erythrocyte sorbitol-glucose ratios by ascorbic acid in diabetes mellitus. Diabetes Res Clin Pract. 1995;28(1):1-8.

43. Paolisso G, Balbi V, Volpe C, et al. Metabolic benefits deriving from chronic vitamin $\mathrm{C}$ supplementation in aged non-insulin dependent diabetics. J Am Coll Nutr. 1995;14(4):387-392.

44. Paolisso G, D'Amore A, Giugliano D, Ceriello A, Varricchio M, D'Onofrio F. Pharmacologic doses of vitamin E improve insulin action in healthy subjects and non-insulin-dependent diabetic patients. $\mathrm{Am} J$ Clin Nutr. 1993;57(5):650-656.

45. Rizzo MR, Abbatecola AM, Barbieri M, et al. Evidence for antiinflammatory effects of combined administration of vitamin $\mathrm{E}$ and $\mathrm{C}$ in older persons with impaired fasting glucose: impact on insulin action. J Am Coll Nutr. 2008;27(4):505-511.

46. Carta S, Castellani P, Delfino L, Tassi S, Vene R, Rubartelli A. DAMPs and inflammatory processes: the role of redox in the different outcomes. J Leukoc Biol. 2009;86(3):549-555.

47. Navab M, Gharavi N, Watson AD. Inflammation and metabolic disorders. Curr Opin Clin Nutr Metab Care. 2008;11(4):459-464.

48. Beatty S, Koh H, Phil M, Henson D, Boulton M. The role of oxidative stress in the pathogenesis of age-related macular degeneration. Surv Ophthalmol. 2000;45(2):115-134.

49. Takeda K, Akira S. TLR signaling pathways. Semin Immunol. 2004; 16(1):3-9. 
50. Baumann H, Gauldie J. The acute phase response. Immunol Today. 1994;15(2):74-80.

51. Steel DM, Whitehead AS. The major acute phase reactants: C-reactive protein, serum amyloid $\mathrm{P}$ component and serum amyloid A protein. Immunol Today. 1994;15(2):81-88.

52. Gabay C, Kushner I. Acute-phase proteins and other systemic responses to inflammation. N Engl J Med. 1999;340(6):448-454.

53. Montecucco F, Steffens S, Mach F. Insulin resistance: a proinflammatory state mediated by lipid-induced signaling dysfunction and involved in atherosclerotic plaque instability. Mediators Inflamm. 2008;2008:767623.

54. Aguirre V, Uchida T, Yenush L, Davis R, White MF. The c-Jun NH(2)terminal kinase promotes insulin resistance during association with insulin receptor substrate-1 and phosphorylation of Ser(307). $J$ Biol Chem. 2000;275(12):9047-9054.

55. Guzik TJ, West NE, Black E, et al. Vascular superoxide production by $\mathrm{NAD}(\mathrm{P}) \mathrm{H}$ oxidase: association with endothelial dysfunction and clinical risk factors. Circ Res. 2000;86(9):E85-E90.

56. Guzik TJ, Mussa S, Gastaldi D, et al. Mechanisms of increased vascular superoxide production in human diabetes mellitus: role of NAD(P) $\mathrm{H}$ oxidase and endothelial nitric oxide synthase. Circulation. 2002; 105(14):1656-1662.

57. Vega-Lopez S, Devaraj S, Jialal I. Oxidative stress and antioxidant supplementation in the management of diabetic cardiovascular disease. J Investig Med. 2004;52(1):24-32.

58. Oberg BP, McMenamin E, Lucas FL, et al. Increased prevalence of oxidant stress and inflammation in patients with moderate to severe chronic kidney disease. Kidney Int. 2004;65(3):1009-1016.

59. Ceriello A, Mercuri F, Quagliaro L, et al. Detection of nitrotyrosine in the diabetic plasma: evidence of oxidative stress. Diabetologia. 2001; 44(7):834-838.

60. Dunlop M. Aldose reductase and the role of the polyol pathway in diabetic nephropathy. Kidney Int Suppl. 2000;77:S3-S12.

61. Kashiwagi A, Asahina T, Ikebuchi M, et al. Abnormal glutathione metabolism and increased cytotoxicity caused by $\mathrm{H}_{2} \mathrm{O}_{2}$ in human umbilical vein endothelial cells cultured in high glucose medium. Diabetologia. 1994;37(3):264-269.

62. Scott JA, King GL. Oxidative stress and antioxidant treatment in diabetes. Ann N Y Acad Sci. 2004;1031:204-213.

63. Ceriello A, Testa R. Antioxidant anti-inflammatory treatment in type 2 diabetes. Diabetes Care. 2009;32 Suppl 2:S232-S236.

64. Rask-Madsen C, King GL. Proatherosclerotic mechanisms involving protein kinase $\mathrm{C}$ in diabetes and insulin resistance. Arterioscler Thromb Vasc Biol. 2005;25(3):487-496.

65. Turko IV, Marcondes S, Murad F. Diabetes-associated nitration of tyrosine and inactivation of succinyl-CoA:3-oxoacid CoA-transferase. Am J Physiol Heart Circ Physiol. 2001;281(6):H2289-H2294.

66. Browning LM, Jebb SA. Nutritional influences on inflammation and type 2 diabetes risk. Diabetes Technol Ther. 2006;8(1):45-54.

67. Marfella R, Quagliaro L, Nappo F, Ceriello A, Giugliano D. Acute hyperglycemia induces an oxidative stress in healthy subjects. $J$ Clin Invest. 2001;108(4):635-636.

68. Douillet C, Bost M, Accominotti M, Borson-Chazot F, Ciavatti M. Effect of selenium and vitamin E supplementation on lipid abnormalities in plasma, aorta, and adipose tissue of Zucker rats. Biol Trace Elem Res. 1998;65(3):221-236.

69. Paolisso G, Gambardella A, Tagliamonte MR, et al. Does free fatty acid infusion impair insulin action also through an increase in oxidative stress? J Clin Endocrinol Metab. 1996;81(12):4244-4248.

70. Itani SI, Ruderman NB, Schmieder F, Boden G. Lipid-induced insulin resistance in human muscle is associated with changes in diacylglycerol, protein kinase C, and IkappaB-alpha. Diabetes. 2002; 51(7):2005-2011.

71. Rudich A, Tirosh A, Potashnik R, Khamaisi M, Bashan N. Lipoic acid protects against oxidative stress induced impairment in insulin stimulation of protein kinase B and glucose transport in 3T3-L1 adipocytes. Diabetologia. 1999;42(8):949-957.
72. Rudich A, Kozlovsky N, Potashnik R, Bashan N. Oxidant stress reduces insulin responsiveness in 3T3-L1 adipocytes. Am J Physiol. 1997; 272(5 Pt 1):E935-E940.

73. Tirosh A, Rudich A, Potashnik R, Bashan N. Oxidative stress impairs insulin but not platelet-derived growth factor signalling in 3T3-L1 adipocytes. Biochem J. 2001;355(Pt 3):757-763.

74. Haber CA, Lam TK, Yu Z, et al. N-acetylcysteine and taurine prevent hyperglycemia-induced insulin resistance in vivo: possible role of oxidative stress. Am J Physiol Endocrinol Metab. 2003; 285(4):E744-E753.

75. Bruce CR, Carey AL, Hawley JA, Febbraio MA. Intramuscular heat shock protein 72 and heme oxygenase- 1 mRNA are reduced in patients with type 2 diabetes: evidence that insulin resistance is associated with a disturbed antioxidant defense mechanism. Diabetes. 2003;52(9): 2338-2345.

76. Paolisso G, D'Amore A, Volpe C, et al. Evidence for a relationship between oxidative stress and insulin action in non-insulin-dependent (type II) diabetic patients. Metabolism. 1994;43(11):1426-1429.

77. Ford ES, Mokdad AH, Giles WH, Brown DW. The metabolic syndrome and antioxidant concentrations: findings from the Third National Health and Nutrition Examination Survey. Diabetes. 2003;52(9): 2346-2352.

78. Lee KU. Oxidative stress markers in Korean subjects with insulin resistance syndrome. Diabetes Res Clin Pract. 2001;54 Suppl 2:S29-S33.

79. Maritim AC, Sanders RA, Watkins JB III. Diabetes, oxidative stress, and antioxidants: a review. J Biochem Mol Toxicol. 2003;17(1): 24-38.

80. King GL. The role of inflammatory cytokines in diabetes and its complications. J Periodontol. 2008;79(8 Suppl):1527-1534.

81. Liu G, Rondinone CM. JNK: bridging the insulin signaling and inflammatory pathway. Curr Opin Investig Drugs. 2005;6(10):979-987.

82. Hundal RS, Petersen KF, Mayerson AB, et al. Mechanism by which high-dose aspirin improves glucose metabolism in type 2 diabetes. J Clin Invest. 2002;109(10):1321-1326.

83. Gumieniczek A, Krzywdzinska M, Nowak M. Modulation of nitrosative/oxidative stress in the lung of hyperglycemic rabbits by two antidiabetics, pioglitazone and repaglinide. Exp Lung Res. 2009;35(5): 371-379.

84. Adameova A, Xu YJ, Duhamel TA, Tappia PS, Shan L, Dhalla NS. Anti-atherosclerotic molecules targeting oxidative stress and inflammation. Curr Pharm Des. 2009;15(27):3094-3107.

85. Fukuzawa M, Satoh J, Qiang X, et al. Inhibition of tumor necrosis factor-alpha with anti-diabetic agents. Diabetes Res Clin Pract. 1999; 43(3):147-154.

86. Delerive P, Fruchart JC, Staels B. Peroxisome proliferatoractivated receptors in inflammation control. J Endocrinol. 2001;169(3): 453-459.

87. Brighenti F, Valtuena S, Pellegrini N, et al. Total antioxidant capacity of the diet is inversely and independently related to plasma concentration of high-sensitivity C-reactive protein in adult Italian subjects. Br J Nutr. 2005;93(5):619-625.

88. Maggini S, Wintergerst ES, Beveridge S, Hornig DH. Selected vitamins and trace elements support immune function by strengthening epithelial barriers and cellular and humoral immune responses. Br J Nutr. 2007; 98 Suppl 1:S29-S35.

89. Soory M. Relevance of nutritional antioxidants in metabolic syndrome, ageing and cancer: potential for therapeutic targeting. Infect Disord Drug Targets. 2009;9(4):400-414.

90. Pittas AG, Harris SS, Stark PC, Dawson-Hughes B. The effects of calcium and vitamin D supplementation on blood glucose and markers of inflammation in nondiabetic adults. Diabetes Care. 2007;30(4): 980-986.

91. Pittas AG, Lau J, Hu FB, Dawson-Hughes B. Review: the role of vitamin $\mathrm{D}$ and calcium in type 2 diabetes. A systematic review and meta-analysis. J Clin Endocriol Metabol. 2007;92(6):2017-2029.

92. Haddad PS, Azar GA, Groom S, Boivin M. Natural health products, modulation of immune function and prevention of chronic diseases. Evid Based Complement Alternat Med. 2005;2(4):513-520. 
93. James MJ, Gibson RA, Cleland LG. Dietary polyunsaturated fatty acids and inflammatory mediator production. Am J Clin Nutr. 2000; 71(1 Suppl):343S-348S.

94. Liu CT, Sheen LY, Lii CK. Does garlic have a role as an antidiabetic agent? Mol Nutr Food Res. 2007;51(11):1353-1364.

95. Weisberg SP, Leibel R, Tortoriello DV. Dietary curcumin significantly improves obesity-associated inflammation and diabetes in mouse models of diabesity. Endocrinology. 2008;149(7):3549-3558.

96. Srinivas L, Shalini VK. DNA damage by smoke: protection by turmeric and other inhibitors of ROS. Free Radic Biol Med. 1991;11(3): 277-283.

97. Srivastava R, Srimal RC. Modification of certain inflammationinduced biochemical changes by curcumin. Indian J Med Res. 1985; 81:215-223.

98. Vuksan V, Stavro MP, Sievenpiper JL, et al. Similar postprandial glycemic reductions with escalation of dose and administration time of American ginseng in type 2 diabetes. Diabetes Care. 2000; 23(9):1221-1226.

99. Sprietsma JE, Schuitemaker GE. Diabetes can be prevented by reducing insulin production. Med Hypotheses. 1994;42(1):15-23.

100. Hashemipour M, Kelishadi R, Shapouri J, et al. Effect of zinc supplementation on insulin resistance and components of the metabolic syndrome in prepubertal obese children. Hormones (Athens). 2009; 8(4):279-285.

101. Song Y, Wang J, Li XK, Cai L. Zinc and the diabetic heart. Biometals. 2005;18(4):325-332.

102. Prasad AS. Zinc in human health: effect of zinc on immune cells. Mol Med. 2008;14(5-6):353-357.

103. Prasad AS, Bao B, Beck FW, Kucuk O, Sarkar FH. Antioxidant effect of zinc in humans. Free Radic Biol Med. 2004;37(8):1182-1190.

104. Botella-Carretero JI, Alvarez-Blasco F, Villafruela JJ, Balsa JA, Vazquez C, Escobar-Morreale HF. Vitamin D deficiency is associated with the metabolic syndrome in morbid obesity. Clin Nutr. 2007; 26(5):573-580.

105. Teegarden D, Donkin SS. Vitamin D: emerging new roles in insulin sensitivity. Nutr Res Rev. 2009;22(1):82-92.

106. Holick MF. Diabetes and the vitamin d connection. Curr Diab Rep. 2008;8(5):393-398.

107. Anan F, Takahashi N, Nakagawa M, Ooie T, Saikawa T, Yoshimatsu H. High-sensitivity C-reactive protein is associated with insulin resistance and cardiovascular autonomic dysfunction in type 2 diabetic patients. Metabolism. 2005;54(4):552-558.

108. Fu L, Yun F, Oczak M, Wong BY, Vieth R, Cole DE. Common genetic variants of the vitamin $\mathrm{D}$ binding protein (DBP) predict differences in response of serum 25-hydroxyvitamin D [25(OH)D] to vitamin D supplementation. Clin Biochem. 2009;42(10-11):1174-1177.

109. Szathmary EJ. The effect of Gc genotype on fasting insulin level in Dogrib Indians. Hum Genet. 1987;75(4):368-372.

110. Hirai M, Suzuki S, Hinokio Y, et al. Variations in vitamin D-binding protein (group-specific component protein) are associated with fasting plasma insulin levels in Japanese with normal glucose tolerance. J Clin Endocrinol Metab. 2000;85(5):1951-1953.

111. Baier LJ, Dobberfuhl AM, Pratley RE, Hanson RL, Bogardus C. Variations in the vitamin D-binding protein (Gc locus) are associated with oral glucose tolerance in nondiabetic Pima Indians. J Clin Endocrinol Metab. 1998;83(8):2993-2996.

112. Pittas AG, Dawson-Hughes B, Li T, et al. Vitamin D and calcium intake in relation to type 2 diabetes in women. Diabetes Care. 2006; 29(3):650-656.

113. Hayes CE, Nashold FE, Spach KM, Pedersen LB. The immunological functions of the vitamin D endocrine system. Cell Mol Biol (Noisy-le-grand). 2003;49(2):277-300.

114. Griffin MD, Xing N, Kumar R. Vitamin D and its analogs as regulators of immune activation and antigen presentation. Annu Rev Nutr. 2003; 23:117-145.

115. Cantorna MT, Zhu Y, Froicu M, Wittke A. Vitamin D status, 1,25dihydroxyvitamin D3, and the immune system. Am J Clin Nutr. 2004; 80(6 Suppl):1717S-1720S.
116. DeLuca HF, Cantorna MT. Vitamin D: its role and uses in immunology. FASEB J. 2001;15(14):2579-2585.

117. Veldman CM, Cantorna MT, DeLuca HF. Expression of 1,25dihydroxyvitamin D(3) receptor in the immune system. Arch Biochem Biophys. 2000;374(2):334-338.

118. Riachy R, Vandewalle B, Kerr Conte J, et al. 1,25-dihydroxyvitamin D3 protects RINm5F and human islet cells against cytokine-induced apoptosis: implication of the antiapoptotic protein A20. Endocrinology. 2002;143(12):4809-4819.

119. Van Etten E, Mathieu C. Immunoregulation by 1,25-dihydroxyvitamin D3: basic concepts. J Steroid Biochem Mol Biol. 2005;97(1-2): 93-101.

120. Pittas AG, Chung M, Trikalinos T, et al. Systematic review: vitamin D and cardiometabolic outcomes. Ann Intern Med. 2010;152(5): 307-314.

121. Chiu KC, Chu A, Go VL, Saad MF. Hypovitaminosis D is associated with insulin resistance and beta cell dysfunction. Am J Clin Nutr. 2004; 79(5):820-825.

122. Ford ES, Ajani UA, McGuire LC, Liu S. Concentrations of serum vitamin D and the metabolic syndrome among US adults. Diabetes Care. 2005;28(5):1228-1230.

123. Hypponen E, Power C. Vitamin D status and glucose homeostasis in the 1958 British birth cohort: the role of obesity. Diabetes Care. 2006; 29(10):2244-2246.

124. Need AG, O'Loughlin PD, Horowitz M, Nordin BE. Relationship between fasting serum glucose, age, body mass index and serum 25 hydroxyvitamin D in postmenopausal women. Clin Endocrinol (Oxf). 2005;62(6):738-741.

125. Scragg R, Sowers M, Bell C. Serum 25-hydroxyvitamin D, diabetes, and ethnicity in the Third National Health and Nutrition Examination Survey. Diabetes Care. 2004;27(12):2813-2818.

126. Liu S, Song Y, Ford ES, Manson JE, Buring JE, Ridker PM. Dietary calcium, vitamin $\mathrm{D}$, and the prevalence of metabolic syndrome in middle-aged and older US women. Diabetes Care. 2005;28(12):2926-2932.

127. Fliser D, Stefanski A, Franek E, Fode P, Gudarzi A, Ritz E. No effect of calcitriol on insulin-mediated glucose uptake in healthy subjects. Eur J Clin Invest. 1997;27(7):629-633.

128. Inomata S, Kadowaki S, Yamatani T, Fukase M, Fujita T. Effect of 1 alpha $(\mathrm{OH})$-vitamin D3 on insulin secretion in diabetes mellitus. Bone Miner. 1986;1(3):187-192.

129. Ljunghall S, Lind L, Lithell H, et al. Treatment with one-alphahydroxycholecalciferol in middle-aged men with impaired glucose tolerance-a prospective randomized double-blind study. Acta Med Scand. 1987;222(4):361-367.

130. Orwoll E, Riddle M, Prince M. Effects of vitamin D on insulin and glucagon secretion in non-insulin-dependent diabetes mellitus. Am J Clin Nutr. 1994;59(5):1083-1087.

131. Nilas L, Christiansen C. Treatment with vitamin D or its analogues does not change body weight or blood glucose level in postmenopausal women. Int J Obes. 1984;8(5):407-411.

132. Knowler WC, Barrett-Connor E, Fowler SE, et al. Reduction in the incidence of type 2 diabetes with lifestyle intervention or metformin. N Engl J Med. 2002;346(6):393-403.

133. Von Hurst PR, Stonehouse W, Coad J. Vitamin D supplementation reduces insulin resistance in South Asian women living in New Zealand who are insulin resistant and vitamin D deficient - a randomised, placebo-controlled trial. Br J Nutr. 2010;103(4): 549-555.

134. Wannamethee SG, Lowe GD, Rumley A, Bruckdorfer KR, Whincup PH. Associations of vitamin $\mathrm{C}$ status, fruit and vegetable intakes, and markers of inflammation and hemostasis. Am J Clin Nutr. 2006; 83(3):567-574.

135. Aguirre R, May JM. Inflammation in the vascular bed: importance of vitamin C. Pharmacol Ther. 2008;119(1):96-103.

136. Levine M, Wang Y, Padayatty SJ, Morrow J. A new recommended dietary allowance of vitamin $\mathrm{C}$ for healthy young women. Proc Natl Acad Sci U S A. 2001;98(17):9842-9846. 
137. Cahill L, Corey PN, El-Sohemy A. Vitamin C deficiency in a population of young Canadian adults. Am J Epidemiol. 2009;170(4):464-471.

138. Young IS, Tate S, Lightbody JH, McMaster D, Trimble ER. The effects of desferrioxamine and ascorbate on oxidative stress in the streptozotocin diabetic rat. Free Radic Biol Med. 1995;18(5):833-840.

139. Ford ES, Liu S, Mannino DM, Giles WH, Smith SJ. C-reactive protein concentration and concentrations of blood vitamins, carotenoids, and selenium among United States adults. Eur J Clin Nutr. 2003;57(9): $1157-1163$

140. Hamer M, Chida Y. Intake of fruit, vegetables, and antioxidants and risk of type 2 diabetes: systematic review and meta-analysis. $J$ Hypertens. 2007;25(12):2361-2369.

141. Woodward M, Lowe GD, Rumley A, et al. Epidemiology of coagulation factors, inhibitors and activation markers: the Third Glasgow MONICA Survey. II. Relationships to cardiovascular risk factors and prevalent cardiovascular disease. Br J Haematol. 1997;97(4): 785-797.

142. Woodward M, Rumley A, Tunstall-Pedoe H, Lowe GD. Associations of blood rheology and interleukin- 6 with cardiovascular risk factors and prevalent cardiovascular disease. Br J Haematol. 1999; 104(2):246-257.

143. Woodward M, Rumley A, Lowe GD, Tunstall-Pedoe H. C-reactive protein: associations with haematological variables, cardiovascular risk factors and prevalent cardiovascular disease. Br J Haematol. 2003 122(1):135-141.

144. Gao X, Bermudez OI, Tucker KL. Plasma C-reactive protein and homocysteine concentrations are related to frequent fruit and vegetable intake in Hispanic and non-Hispanic white elders. J Nutr. 2004; 134(4):913-918.

145. Holt EM, Steffen LM, Moran A, et al. Fruit and vegetable consumption and its relation to markers of inflammation and oxidative stress in adolescents. J Am Diet Assoc. 2009;109(3):414-421.

146. Lu Q, Bjorkhem I, Wretlind B, Diczfalusy U, Henriksson P, Freyschuss A. Effect of ascorbic acid on microcirculation in patients with type II diabetes: a randomized placebo-controlled cross-over study. Clin Sci (Lond). 2005;108(6):507-513.

147. Chen H, Karne RJ, Hall G, et al. High-dose oral vitamin C partially replenishes vitamin $\mathrm{C}$ levels in patients with type 2 diabetes and low vitamin $\mathrm{C}$ levels but does not improve endothelial dysfunction or insulin resistance. Am J Physiol Heart Circ Physiol. 2006; 290(1):H137-H145.

148. Tousoulis D, Antoniades C, Vasiliadou C, et al. Effects of atorvastatin and vitamin $\mathrm{C}$ on forearm hyperaemic blood flow, asymmentrical dimethylarginine levels and the inflammatory process in patients with type 2 diabetes mellitus. Heart. 2007;93(2):244-246.

149. Eriksson J, Kohvakka A. Magnesium and ascorbic acid supplementation in diabetes mellitus. Ann Nutr Metab. 1995;39(4):217-223.

150. Adolfsson O, Huber BT, Meydani SN. Vitamin E-enhanced IL-2 production in old mice: naive but not memory $\mathrm{T}$ cells show increased cell division cycling and IL-2-producing capacity. J Immunol. 2001;167(7):3809-3817.

151. Han SN, Adolfsson O, Lee CK, Prolla TA, Ordovas J, Meydani SN. Vitamin E and gene expression in immune cells. Ann N Y Acad Sci. 2004;1031:96-101.

152. Devaraj S, Jialal I. $\alpha$-Tocopherol decreases interleukin- $1 \beta$ release from activated human monocytes by inhibition of 5-lipoxygenase. Arterioscler Thromb Vasc Biol. 1999;19:1125-1133.

Biologics: Targets \& Therapy

\section{Publish your work in this journal}

Biologics: Targets \& Therapy is an international, peer-reviewed journal focusing on the patho-physiological rationale for and clinical application of Biologic agents in the management of autoimmune diseases, cancers or other pathologies where a molecular target can be identified This journal is indexed on PubMed Central, CAS, EMBase, Scopus
153. Thomas SR, Stocker R. Molecular action of vitamin E in lipoprotein oxidation: implications for atherosclerosis. Free Radic Biol Med. 2000; 28(12):1795-1805.

154. Salonen JT, Nyyssonen K, Tuomainen TP, et al. Increased risk of non-insulin dependent diabetes mellitus at low plasma vitamin $\mathrm{E}$ concentrations: a four year follow up study in men. BMJ. 1995;311(7013): 1124-1127.

155. Reunanen A, Knekt P, Aaran RK, Aromaa A. Serum antioxidants and risk of non-insulin dependent diabetes mellitus. Eur J Clin Nutr. 1998;52(2):89-93.

156. Mayer-Davis EJ, Costacou T, King I, Zaccaro DJ, Bell RA. Plasma and dietary vitamin $\mathrm{E}$ in relation to incidence of type 2 diabetes: the Insulin Resistance and Atherosclerosis Study (IRAS). Diabetes Care. 2002;25(12):2172-2177.

157. Ward NC, Wu JH, Clarke MW, et al. The effect of vitamin E on blood pressure in individuals with type 2 diabetes: a randomized, doubleblind, placebo-controlled trial. J Hypertens. 2007;25(1):227-234.

158. Wu JH, Ward NC, Indrawan AP, et al. Effects of alpha-tocopherol and mixed tocopherol supplementation on markers of oxidative stress and inflammation in type 2 diabetes. Clin Chem. 2007;53(3):511-519.

159. Liu S, Lee IM, Song Y, et al. Vitamin E and risk of type 2 diabetes in the women's health study randomized controlled trial. Diabetes. 2006;55(10):2856-2862.

160. Ble-Castillo JL, Carmona-Diaz E, Mendez JD, et al. Effect of alphatocopherol on the metabolic control and oxidative stress in female type 2 diabetics. Biomed Pharmacother. 2005;59(6):290-295.

161. Reaven PD, Herold DA, Barnett J, Edelman S. Effects of vitamin E on susceptibility of low-density lipoprotein and low-density lipoprotein subfractions to oxidation and on protein glycation in NIDDM. Diabetes Care. 1995;18(6):807-816.

162. Ristow M, Zarse K, Oberbach A, et al. Antioxidants prevent healthpromoting effects of physical exercise in humans. Proc Natl Acad Sci US A. 2009;106(21):8665-8670.

163. Buijsse B, Feskens EJ, Kwape L, Kok FJ, Kromhout D. Both alphaand beta-carotene, but not tocopherols and vitamin C, are inversely related to 15-year cardiovascular mortality in Dutch elderly men. J Nutr. 2008;138(2):344-350.

164. Devaraj S, Leonard S, Traber MG, Jialal I. Gamma-tocopherol supplementation alone and in combination with alpha-tocopherol alters biomarkers of oxidative stress and inflammation in subjects with metabolic syndrome. Free Radic Biol Med. 2008;44(6):1203-1208.

165. Belisle SE, Leka LS, Delgado-Lista J, Jacques PF, Ordovas JM, Meydani SN. Polymorphisms at cytokine genes may determine the effect of vitamin E on cytokine production in the elderly. J Nutr. 2009; 139(10): 1855-1860.

166. Barclay C, Procter KL, Glendenning R, Marsh P, Freeman J, Mathers N. Can type 2 diabetes be prevented in UK general practice? A lifestyle-change feasibility study (ISAIAH). Br J Gen Pract. 2008; 58(553):541-547.

167. Norris SL, Zhang X, Avenell A, et al. Long-term effectiveness of weight-loss interventions in adults with pre-diabetes: a review. Am J Prev Med. 2005;28(1):126-139.

168. Frost G, Leeds A, Trew G, Margara R, Dornhorst A. Insulin sensitivity in women at risk of coronary heart disease and the effect of a low glycemic diet. Metabolism. 1998;47(10):1245-1251.

169. Willcox BJ, Curb JD, Rodriguez BL. Antioxidants in cardiovascular health and disease: key lessons from epidemiologic studies. Am J Cardiol. 2008;101(10A):75D-86D.

\section{Dovepress}

and the Elsevier Bibliographic databases. The manuscript management system is completely online and includes a very quick and fair peerreview system, which is all easy to use. Visit http://www.dovepress. com/testimonials.php to read real quotes from published authors. 